\title{
Operational Process of the Internal Quality Assurance Network: Suan Sunandha Rajabhat University
}

\author{
Terada Pinyo and Phoithong Sakhornwannasak
}

\begin{abstract}
The research is a survey study, aiming to study the operational process of the internal quality assurance network at Suan Sunandha Rajabhat University. A questionnaire is used to interview the 18 members from 6 networks, both inside and outside the university. The data is analyzed via contentment analysis; meanwhile, the manual is evaluated and approved by the absolute consensus of the network board. The research result reveals that: 1) the operational process consists of 4 steps, namely, the member recruitment-unit survey, representative nomination, and committee appointment; the cooperation with the network-issue survey for knowledge sharing, network operation planning, network committee meeting and good knowledge and procedure; the following-up and evaluation-operation following-up, achievement assessment, and operation publicity; and the operation review-network operation summary, and working review for next year. 2) the quality assurance manual; consisting of objective, framework, definition of terms, responsibility, criteria and important indicator, reference, flow chart, and procedure has been approved by the consensus of the board and can be used for operation.
\end{abstract}

Index Terms-Network, operational process, internal educational quality assurance.

\section{INTRODUCTION}

The 1999 National Education Act $\left(2^{\text {nd }}\right.$ and $3^{\text {rd }}$ revised versions in 2002 and 2010), chapter 6 concerning the educational standards and quality assurance, section 48 has stated that "Internal quality assurance shall be regarded as part of educational administration which must be continuous process"; and section 50 has also stated that "the educational institutions shall lend co-operation in preparation of documents and evidence providing relevant information on institutions [1]."

Suan Sunandha Rajabhat University has realized the importance and necessity of quality assurance; the system and mechanism for the internal assurance have been set. The implementation is conducted continuously under the supervision of the Department of Planning and Policy. To make the implementation throughout the university in a harmonious direction, the policy on education quality was announced on 15 August 2013. In item 5, it was identified that the activity concerning quality assurance must be carried out as a knowledge management activity, having cooperation among units, staffs, personnel, and organizations from both inside and outside the university [2]. Owing to the results from the internal quality assurance assessment during 2010

Manuscript received December 4, 2014; revised February 3, 2015.

The authors are with Suan Sunandha Rajabhat University, Bankok, Thailand (e-mail: terada.pi@ ssru.ac.th, phoithong.sa@ ssru.ac.th).
2012, 3 from the 6 academic management units got a decrease tendency - the Faculty of Science and Technology, the Faculty of Management Science and the Faculty of Industrial Technology; meanwhile, 5 got a good level result (3.51-4.50) - the Faculty of Education, the Faculty of Sciences and Technology, the Faculty of Humanities and Social Sciences, the Faculty of Industrial Technology, and the Faculty of Fine and Applied Arts (Fig. 1).

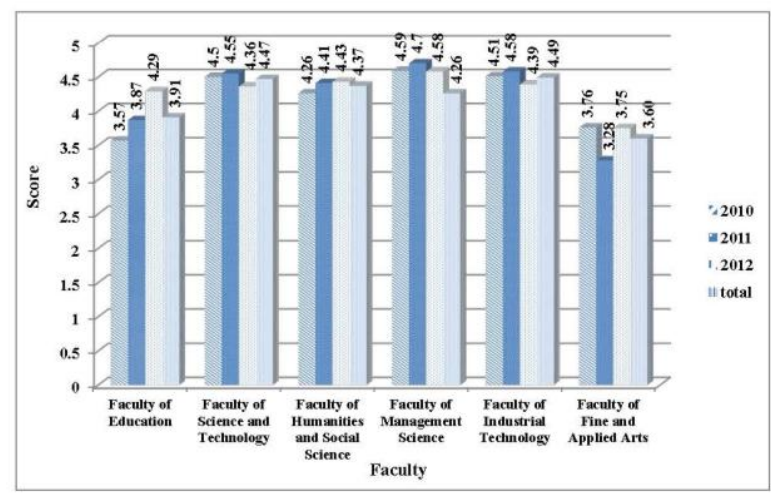

Fig. 1. The internal quality assurance assessment result 2010-2012.

According to the result, the Planning and Policy Division (PPD), which is in charge of the quality assurance, has set up a meeting and analyzed the operations problems of those units. Obviously, the major problem is the perception of the personnel in charge is not in line with the assessment criteria and the evidence papers of operations are not completed and consistent. To eliminate the said problem, the information and data exchanges; and the willingness to cooperate among staff via quality assurance network are very important. In the past, the operational process of the internal quality assurance has not been implemented. As a result, the model for the operational process of the internal quality assurance is focused for conducting the research.

\section{OBJECTIVES}

1) To study the operational process of the internal quality assurance at Suan Sunandha Rajabhat University

2) To evaluate the appropriateness of the internal quality assurance manual

\section{DEFINITION OF TERMS IN THIS STUDY}

Operational process of the internal quality assurance means the operational process that is cooperatively and systematically conducted to develop and improve the quality of Suan Sunandha Rajabhat University in accordance with the education standards, having 4 steps - member recruitment, 
cooperation with the network, following-up and evaluation, and operation review.

Quality work procedure means the flow chart illustrating the steps of operation from the beginning through the end, with a clear practice in every single step.

Quality assurance manual means the document describing procedure and process of every step, with a clear cut who, what, when so that the operator can accurately work and follow every step smoothly.

\section{THEORY AND LITERATURE REVIEW}

The research focuses on the study of the operational process of the internal quality assurance at Suan Sunandha Rajabhat University in accordance with PDCA cycle and quality assurance (Fig. 2) [3]; and Network Theory of Adam Burke [4]; and Kriengsak Chareonwongsak (Fig. 3) [5]. The ISO 9001:2000 Quality Manual is also studied (Fig. 4) [6].

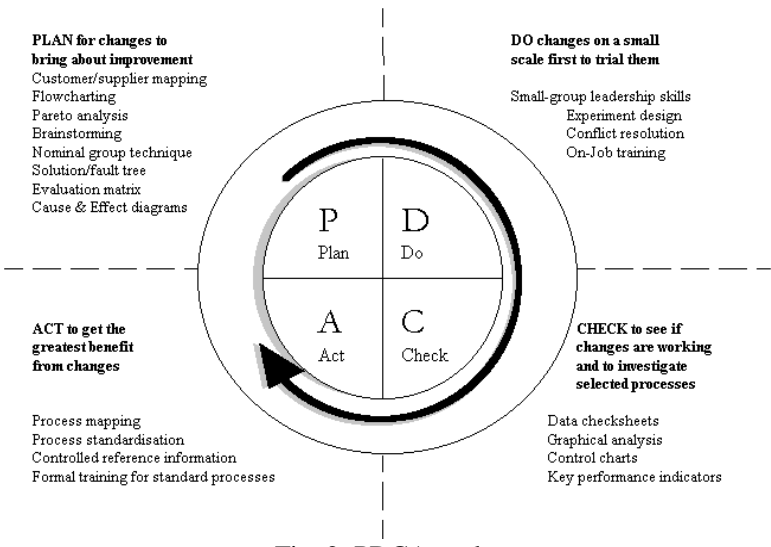

Fig. 2. PDCA cycle.

From Fig. 2 PDCA Cycle consists: 1) plan for Changes to bring about improvement, customer/supplier mapping, flowcharting, pare to analysis, brainstorming, nominal group technique, solution/fault tree, evaluation matrix, cause \& effect diagrams; 2) do changes on a small scale first to trial them, small-group leadership skills, experiment design, conflict resolution, on-job training; 3) check to see if changes are working and to investigate selected processes, data check sheets, graphical analysis, control charts, key performance indicators; 4) act to get the greatest benefit from changes, process mapping, process standardization, controlled reference information, formal training for standard processes.

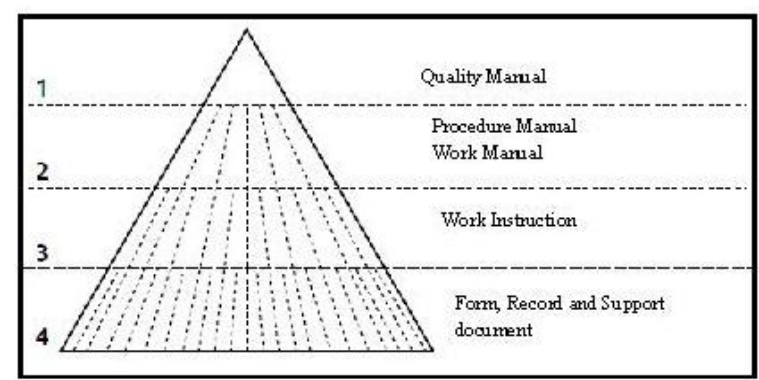

Fig. 3. Organizational structure of the document.

From Fig. 3 Organizational structure of the document consists: 1) quality Manual; 2) procedure manual, work manual; 3) work instruction; 4) from, record and support document.
1. Linking individual to individual

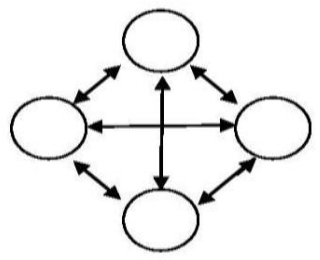

2. Linking the individual to the group

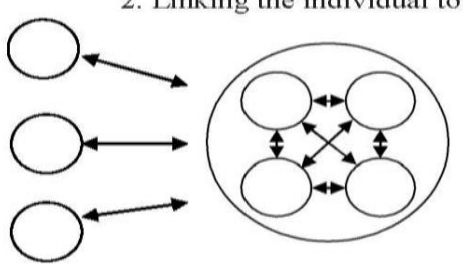

3. Link of the segment

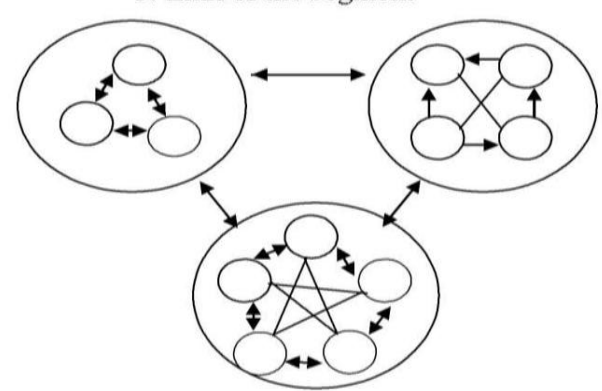

4. Linking networks to networks

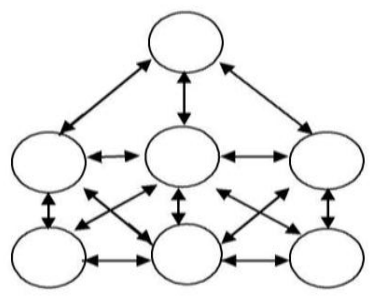

Fig. 4. Characteristics of the network between the individual / group / organization category.

\section{METHODOLOGY}

1) This research is a survey study. The population is 18 network group members from quality assurance, EdPEX and PR, who works with the university and members from outside the university - quality assurance from Silapakorn University, the Academic Resource Services, and Registrar Offices from all over the country.

2) The variable is the operational process of the internal quality assurance at Suan Sunandha Rajabhat University.

3) The tools used are open-ended questionnaire; brainstorming; quality work procedure.

4) Content validity is used for the assessment of research tool.

5) An interview questionnaire is used for collecting data.

6) The data from brainstorming is used to analyze and summarize the operational process, including the quality work procedure and the content validity.

7) Publish the quality assurance manual according to ISO 9001:2000 Quality requirements; and the absolute approval and recommendation of the 80 members of 
network committee board.

\section{RESULT}

The operational process of the internal quality assurance consists of 4 steps: 1) member recruitment - unit survey, representative nomination, and committee appointment; (Fig. 5) 2) cooperation with the network - issue survey for knowledge sharing, network operation planning, network committee meeting and good knowledge and procedure; (Fig. 6) 3) following-up and evaluation - operation following - up, achievement assessment, and operation publicity; (Fig. 7) and 4) operation review - network operation summary, and working review for next year. (Fig. 8)

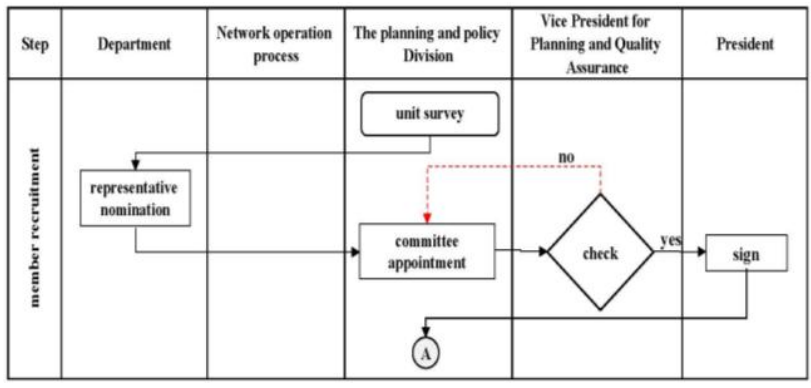

Fig. 5. Step 1 member recruitment.

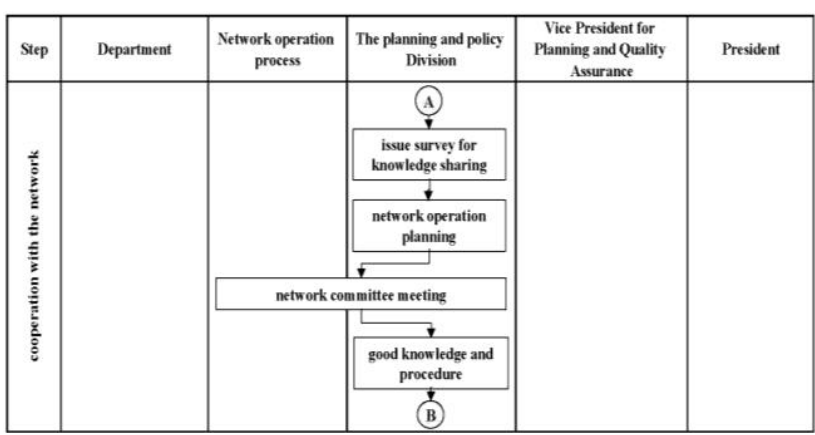

Fig. 6. Step 2 cooperation with the network.

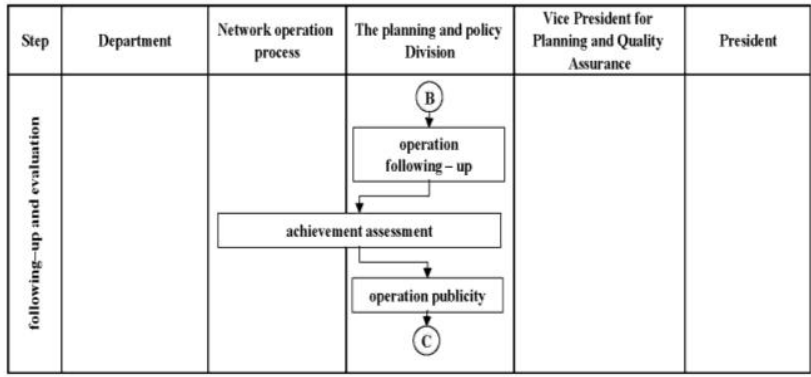

Fig. 7. Step 3 following-up and evaluation.

\begin{tabular}{|c|c|c|c|c|c|}
\hline Step & Department & $\begin{array}{l}\text { Network operation } \\
\text { process }\end{array}$ & $\begin{array}{c}\text { The planning and policy } \\
\text { Division }\end{array}$ & $\begin{array}{c}\text { Vice President for } \\
\text { Planning and Quality } \\
\text { Assurance }\end{array}$ & President \\
\hline \multirow{4}{*}{ 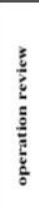 } & & & c) & & \\
\hline & & & $\begin{array}{l}\text { network operation } \\
\text { summary }\end{array}$ & & \\
\hline & & & $\checkmark$ & & \\
\hline & & & $\begin{array}{l}\text { working review for } \\
\text { next year }\end{array}$ & & \\
\hline
\end{tabular}

Fig. 8. Step 4 operation review.

The quality assurance manual, according to the ISO 9001:2000 requirements, consists of: 1) objective; 2) framework; 3) definition of term; 4) responsibility; 5) criteria and important indicators; 6) reference; 7) flow chart; and 8) procedure. The absolute consensus has approved that the manual is appropriate to use.

\section{DISCUSSION}

According to the findings, it can be identified the process of the internal quality assurance, consisting of member recruitment; cooperation with the network; following-up and evaluation; and operation review, should enhance all parties concerned to similarly understand the goal, coordinate and cooperate on the operation, and share the resources consistently. This is in line with Ruk Klong U-tapao Network that begins with the goal value identification of the members; then, each member can adjust oneself according to individual potential / skill in order to serve the needs of the network. The network model is portrayed in the form of horizontal management with cooperation from all parts by storming human resources, intellectual, competency and resources to come across the weak points of bureaucracy, which is the same today's concept of development - Area, Function, Participation [7]. Sermsak Visalaporn et al. commented that network construction based on the National Education Act (1999), section 9 - structure and education management, as follows: 1) Unity in policy and diversity in implementation; 2) Decentralization of authority to educational service areas; 3 ) Setting of educational standards; 4) Developing professional standards on a continuous basis; 5) Mobilization of resources; and 6) Partnerships with individuals, families, communities, community organizations, local administration organizations, private persons, private organizations, professional bodies, religious institutions, enterprises, and other social institutions [8].

According to the findings, quality assurance manual consists of: 1) objective; 2) framework; 3) definition of term; 4) responsibility; 5) criteria and important indicators; 6) reference; 7) flow chart; and 8) procedure. This is in line with Prawes Yodying's comment [9], “...the ISO 9001:2000 consists of - 1) name of the operation; 2) objective; 3) framework; 4) definition; 5) steps; 6) method; and 7) reference..." also comment that the factors of operating manual are: 1) objectives; 2) scope; 3) definition; 4) responsibilities; 5) procedure; 6) reference document; and 7) form [10]. The network committee has considered and absolutely approved that the manual is appropriate to be used. This approval is backed-up by the work of Vanasnat Prapala concerning the approval of quality assurance manual by administrators of Bangkok Community College [11].

\section{SUGGESTION}

The operational process of the internal quality assurance should be publicized to and applied by administrators, in particular the factors for success that can be used for future improvement.

The effects of the operational process of the internal quality assurance should be focused to improve the future process.

\section{ACKNOWLEDGMENT}

The team would like to thank for the kindly support of the 
president, vice-president for planning and quality assurance, and vice-president for research and development, personnel development fund committee, and all staff who provide the information of this research.

\section{REFERENCES}

[1] Ministry of Education. (January 2014). National Education Act (1999). [Online]. p. 9. Available: http://moe.go.th

[2] Planning and Policy Department, The Announcement on Quality Assurance, Bangkok, Thailand: Suan Sunandha Rajabhat University, 2014.

[3] S. Darbavasu et al., Development of Academic Administration Process of the Basic Education Schools Based on the Quality Management Concept, Bangkok, Suan Sunandha Rajabhat University, 2012, pp. 11-13.

[4] A. Burke, Communications \& Development: A Practical Guide, Social Development Division Department for International Development, London, 1999, pp. 76-79.

[5] K. Chareonwongsak, Network Management: Strategic Importance to the Success of Education Reform, Bangkok, Thailand: Asia Press, 2002, p. 30.

[6] J. Yoadrakang, Preparation of Operations Manual, Bangkok, Thailand: Royal Gazette Publishing, 2009, p. 29.

[7] S, Pongpit, Network, Bangkok, Thailand: Chulalongkorn University Book Center, 2002, p. 209.

[8] S. Visalaporn et al., The Form of Network for Teachers and Education Personnel in Accordance with the 2002 National Education Act,

Office of the Teacher Civil Service and Educational Personnel Commission, Bangkok Thailand, 2002, p. 70.

[9] P. Yodying, The ISO 9000 Quality Management System ISO 9000 . 2000, SE-ED Education, Bangkok, Thailand, 2002, pp. 71-80.

[10] Office of the Public Sector Development Commission, "Manual to evaluate the performance of office," Bangkok, Thailand, 2010, p. 29.

[11] P. Wanussanath, "The development quality assurance process of Bangkok Community College by benchmarking process," M.S. thesis, Dept. Quality Management, Suan Sunandha Rajabhat Univ., Bangkok, Thailand, 2009.
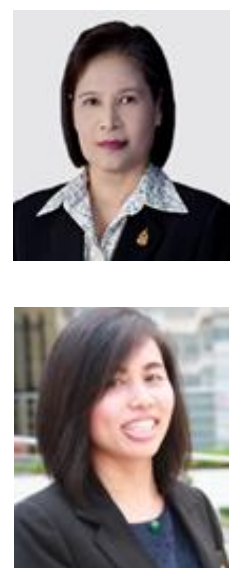

Terada Pinyo was born on May 2, 1954 in Bangkok, Thailand. She got the bachelor's degree in education with science major and master's in education research (statistics). She is now an associate professor in statistics at Suan Sunandha Rajabhat University, teaching statistics at the baccalaureate and master levels. She mainly focuses on research works with concentration on education statistics.

Phoithong Sakhornwannasak was born on December 23, 1984 in Bangkok, Thailand. She has the master's in education, the Dept. Quality Management at Suan Sunandha Rajabhat University. She is an academic officer at the Planning and Policy Division, Office of the President Suan Sunandha Rajabhat University. She mainly focuses on research works with quality assurance and knowledge management. 